\title{
A ANTROPOFAGIA DE OSWALD DE ANDRADE NA CONSTRUÇÃO DA IDEIA DE NACIONALIDADE BRASILEIRA
}

\author{
Patrícia Marcondes de Barros ${ }^{1}$
}

\section{Resumo}

Este artigo trata da ideia de nacionalidade brasileira presente na literatura oswaldiana, especificamente, o conceito de antropofagia cultural tomado como base no delineamento de novas formas para entender o país que se desejava moderno e futuro Éden da humanidade.

Palavras-chave: Modernismo, antropofagia cultural, Oswald de Andrade, literatura, identidade nacional.

\begin{abstract}
The aim of this article is to discuss the idea of Brazilian national identity in the Oswald de Andrade's concept of cultural anthropophagy. We take it as a basis for creating new forms to understand the country which wants to be modern and to become the future humanity's Eden.
\end{abstract}

Palavras-chave: Modernism, cultural anthropophagy, Oswald de Andrade, literature, national identity.

HISTORINHA DO BRASIL

Do Diário de um Tupiniquim

18/12/1499 - A vida é boa, mas muito quente. Não tem sorvetes nem ventiladores. O Brasil é um país perdido. De hoje a uma semana é dia de Natal.

23/04/1500 - O Brasil é um país achado. Desde ontem, quarta, de tarde, que eu desconfiava. Quando estava pensamenteando na praia à hora do crepúsculo bem me pareceu que tinha navios ancorados à distância. Hoje os navios se achegaram e mandaram emissários à terra. São portugueses. Eu preferia os ingleses, povo mais organizado e esportivo. Em todo caso vamos ver com esses mesmos o que é que se faz. Os portugueses são de pano e sentimentais. [...] O principal deles disse que o comandante nos enviava muito saudar. Em resposta tive ocasião de proferir o seguinte aplaudido discurso: "Senhores descobridores, excelentíssimas patrícias, meus amigos - O Brasil é um vasto hospital hospitaleiro, sempre pronto a receber de braços abertos, como o Cruzeiro do Sul, os seus verdadeiros amigos. Façam de conta que a terra é sua e juntos, pois a união faz a força, trabalhemos para a grandeza e a prosperidade das nossas pátrias. O dia de ontem ficará assinalado entre os mais gloriosos da História" $[\ldots]$.

9/8/1502 - O homem que não sabe reconhecer o bem que lhe fazem é um ingrato. Os portugueses afinal não são tão esquisitos como dizem. São muito cultos. Falam como se escreve. No mais as aparências enganam. O pano sai e tem carne por debaixo. Por sinal que é tenra e de fácil digestão. São uns águias. Descobriram que a baía de Guanabara é um rio (isso só de português...) e que no Brasil tem costas largas e riquezas. Daqui de onde escrevo estou vendo um branco e um bronze. Comidas...

26/2/15 - Agora tem homens cor de noite. Os filhos dos brancos não são tão brancos e alguns começam a dizer que o Reino não existe, uma ova e que o seu a seu dono. Ora, dono por dono, eu também sou dono. Logo, a propriedade é um roubo.

\footnotetext{
${ }^{1}$ Doutora em História pela UNESP, pesquisadora do Laboratório de estudos e pesquisas em história, moda e cultura, da Universidade Estadual de Maringá. E-mail: patriciamarcondesdebarros@ gmail.com.
} 
Novembro de 1889 - O Marechal Deodoro de barbas a cavalo proclamou a república e avisou que todos são iguais perante a lei. Iguais a quê?

19 ... - "Não era esta a república dos meus sonhos".

(Prudente de Moraes - 19/12/1925 - O mês modernista - jornal A Noite)

\section{O Matriarcado de Pindorama e a formulação de um país moderno}

Como se deve escrever a história do Brasil? Certamente cada geração reescreve sua história de acordo com suas demandas sociais e seus principais artífices são geralmente as instituições de saber, os jornalistas, os historiadores e os artistas que delineiam a sensibilidade de uma época. No século XIX, com a experiência das exposições universais tentou-se vender uma imagem progressista do Brasil, que, contudo, se destacava pelo seu exotismo e não propriamente da imagem idealizada pelo imperador D. Pedro II.

Com a Proclamação da República no século XX, procurava-se mais do que nunca projetar a ideia de um país moderno, independente e principalmente brasileiro. Mas o que era ser brasileiro? A imagem de uma população multirracial, de preponderância negra e índia junto a uma elite ilustrada (composta em sua maioria por filhos de europeus) não seria um modelo para a mentalidade que se desejava moderna e desenvolvida.

A formação dos pensadores brasileiros no início do século $\mathrm{XX}$ se deve à ciência, considerada como paradigma central da sociedade ocidental moderna para se apreender a realidade e que se fundava em cinco critérios principais: determinismo, racismo, evolucionismo, cientificismo e progresso social. A “inferioridade" de negros e índios foi construída e legitimada por teorias raciais, que os associavam a raças primitivas e degeneradas, com hábitos "não civilizados".

Desta forma, o Brasil podia ser visualizado pela elite ilustrada brasileira como um país promissor que, contudo, carregava em seu interior a "doença" do subdesenvolvimento e primitividade, que teria de ser "curada", higienizada e disciplinada para "a ordem e o progresso" brasileiros. Assim, forjava-se uma identidade nacional através da política do branqueamento, amparada por teorias científicas, visando à formação de um país branco e desenvolvido. $\mathrm{O}$ Brasil seria apresentado internacionalmente como um "Eldorado", e isto chamou muito a atenção de imigrantes que procuravam terras e uma vida melhor. Através do contato miscigenador do europeu com o negro, este último adquiriria todas as virtudes europeias, como laboriosidade, assiduidade, higiene, disciplina, entre outros fatores imprescindíveis para a construção de um país moderno e desenvolvido. 
Em São Paulo consegue-se visualizar com precisão o caráter de modernização pelo qual a cidade, antes cafeeira, geradora de muitas riquezas, havia passado. Com o capital acumulado do café, gerou-se a industrialização, que dava outro aspecto, não só à cidade de São Paulo, mas a seus habitantes. Unidos pela natureza selvagem das chaminés e dos relógios que ordenavam pontualmente a vida daqueles desenraizados, já não eram italianos, espanhóis, japoneses e nem migrantes de outras regiões; eram apenas personagens da modernidade que fazia da cidade uma metrópole.

A cidade passaria a ser vista tal como Ronald de Carvalho, escritor modernista, a descreveu: "Há quem tenha a ilusão de que São Paulo é o café. Puro engano. São Paulo era a máquina, o tear, a polia, a vertigem das energias novas, uma das forças propulsoras da nacionalidade" (Apud ANDRADE, 1944, p. 94). São Paulo seria a cidade brasileira mais apropriada para o desenvolvimento industrial e, com ele, a instauração da modernização brasileira:

[...] São Paulo não era uma cidade nem de negros, nem de brancos e nem de mestiços; nem de estrangeiros e nem de brasileiros; nem americana, nem europeia, nem nativa; nem era industrial, apesar do volume crescente das fábricas, nem entreposto agrícola, apesar da importância crucial do café; não era tropical, nem subtropical; não era ainda moderna, mas já não tinha mais passado. Essa cidade que brotou súbita e inexplicavelmente, como um colossal cogumelo depois da chuva, era um enigma para seus próprios habitantes, perplexos, tentando entendê-lo como podiam, enquanto lutavam para não serem devorados... (SEVCENKO, 1992, p.31).

A lógica industrial não somente ordenou os espaços da cidade, dando-lhes um sentido, mas também despertou novos comportamentos em seus habitantes, fascinados e assustados com o vulto modernizador que se abateu sobre aquilo que mais parecia uma torre de babel: imigrantes europeus, migrantes que vinham do interior para as cidades, artistas de outras regiões brasileiras que precisavam da agitação e do turbilhão de acontecimentos característicos da modernidade brasileira que ali se originava.

Essa "Babel" agregadora de muitos desenraizados logo se transformaria, segundo Sevcenko (1992), num "Cativeiro da Babilônia", devido à situação precária e desumana de trabalho que milhares de pessoas enfrentavam no seu dia a dia. Contudo, havia as máquinas, os carros, os bondes e outros aspectos modernizantes que alterariam o imaginário dos habitantes da cidade, mostrando-lhes "os benefícios do progresso" e, ao mesmo tempo, domesticando comportamentos. Havia a promessa estampada na vitrine moderna e urbana - mas só depois de muito trabalho, pois "o trabalho dignificaria o homem" - dos momentos de folga, cinema, tardes 
no jóquei clube, pescaria no rio Tietê, roupas novas ou quem sabe, dar um pulinho no Clube Paulistano.

Gripes epidêmicas, geadas, sanitarização, greves (indícios da modernização nas relações de trabalho, com operários reivindicando melhores salários e menos horas em suas jornadas diárias), Primeira Guerra Mundial e a impressão de um mundo mais rápido (com seus novos inventos que alterariam para sempre o conceito de tempo e espaço), confortavelmente inquietante, antecipariam os anos 1920. A década de 1920 revolucionou a arte e a literatura com o modernismo instaurado com a Semana de 22 e a pretensão de uma nova denominação do que era ser brasileiro.

Com a expansão do café desenvolveu-se uma burguesia paulistana, que vivia no eixo Europa-São Paulo. Através desse contato iam adquirindo não apenas novas experiências no campo artístico, mas também redescobrindo um Brasil visto a partir da Europa, amplificando a consciência do nacional e a noção de pertencimento a uma cultura pluri-identitária. Em relação a esse sentimento de "redescoberta", Paulo Prado escreve no prefácio do livro de poemas Paubrasil (1928), escrito por Oswald de Andrade, um dos protagonistas do que seria chamado de modernismo literário:

[...] A poesia "pau-brasil" é o ovo de Colombo - esse ovo [...] em que ninguém acreditava e que acabou enriquecendo o genovês. Oswald de Andrade, numa viagem a Paris, do alto de um ateliê da Place Clichy - umbigo do mundo - descobriu, deslumbrado, a própria terra. A volta à pátria confirmou, no encantamento das descobertas manuelinas, a revelação surpreendente de que o Brasil existia. Esse fato, de que alguns já desconfiavam, abriu seus olhos à visão radiosa de um mundo novo, inexplorado e misterioso. Estava criada a poesia pau-brasil (PRADO apud SEVCENKO, 1992, p.295).

Essa geração de burgueses, anárquicos da literatura, artistas plásticos, músicos, entre outros protagonistas, influenciada pelo ideário europeu do "futurismo" e no afã característico de habitantes de um lugar que, de uma aldeia jesuítica se transformou em metrópole, buscava trazer para o Brasil novas formas de sentir a nacionalidade, baseada num ritual antigo de nossos "nativos primitivos": a antropofagia, que inseria através da "deglutição cultural" a assimilação das "boas qualidades" do "inimigo devorado".

\section{“Não existe pecado no lado de baixo do Equador: a Alegria é a prova dos nove"}

Só a Antropofagia nos une. Socialmente. Economicamente. Filosoficamente. Única lei do mundo. Expressão mascarada de todos os individualismos, de todos os coletivismos. De todas as religiões. De todos os tratados de paz. Tupi or not tupi, that 
is the question. Contra todas as catequeses. E contra a mãe dos Gracos. Só me interessa o que não é meu. Lei do homem. Lei do antropófago [...] (ANDRADE, 1980).

A esta nova forma de ser e pensar a nacionalidade brasileira deu-se o nome de modernismo, que rompeu com os antigos paradigmas veiculados pelas artes e literatura realista, naturalista e parnasiana, surgidas no final do século XIX. As correntes literárias do Realismo e Naturalismo faziam uma crítica objetiva à realidade num combate à estrutura e aos valores da sociedade burguesa. O Parnasianismo era uma arte burguesa, buscava o belo, perseguia a estética com uma temática clássica oriunda da arte greco-romana e com uma preocupação excessiva com a métrica e com a academia. No Brasil, Olavo Bilac tentaria encaixar nos versos "brônzeos", motivos nacionalistas, eternizando heróis nacionais como se fossem estátuas.

Oswald de Andrade manifestaria sua irritabilidade contra o Parnasianismo, alicerçando a sua ideia de modernismo:

[...] É sobretudo contra o parnasianismo que Oswald de Andrade assenta sua metralhadora giratória ao fazer a defesa da língua sem arcaísmo, sem erudição. Natural e neológica. A contribuição milionária de todos os erros. Como falamos. Como somos... Só não se inventou uma máquina de fazer versos - havia o poeta parnasiano (ANDRADE apud MIRANDA, 1997, p.137).

O Modernismo surge como um movimento de espírito polêmico e demolidor que buscava a originalidade a qualquer preço e que seria um reflexo daqueles "novos tempos" na literatura e nas artes, caracterizados pelo rompimento com as tradições acadêmicas, pela liberdade de criação e de pesquisa estética, e pela busca de fundamentação nas fontes mais autênticas da cultura e da realidade brasileira (PELEGRINI, 1993, p. 61). Introduziu na literatura uma liberdade de forma e linguagem, utilizando-se do verso livre, do fragmento e da linguagem coloquial. O modernismo representaria a liberdade de cada poeta para eleger suas próprias regras, sem a imposição das academias. O aspecto revolucionário do Modernismo pode ser comparado ao Romantismo:

[...] O Movimento Romântico é tão inovador quanto o Moderno. O primeiro subverteu a ordem clássica, enquanto o segundo subverteu as tradições acadêmicas. Parece existir certa cumplicidade entre os dois. O romantismo introduz o "pobre" nos romances, o modernismo aprofunda tal postura, incorporando a própria linguagem deste homem (PELEGRINI, 1993, p.62).

O romantismo alicerçava-se no nacionalismo e procurava gerar códigos identitários que expressassem o conteúdo humano da sociedade que ansiava, como no caso brasileiro, ser “civilizada" e "independente" organizando-se, contudo, aos parâmetros europeus ocidentais. Já 
o Movimento Modernista expressar-se-ia através de temáticas onde fosse evidenciado o ambiente das cidades, buscando raízes próprias, mas concomitantemente expressando uma poesia emancipada, "primitiva e brasileira".

A chamada Semana de 22, realizada em São Paulo, foi considerada um marco na história da arte contemporânea no Brasil, manifestação de revolta contra a academia e a sociedade de "fazendeiros-urbanos" e "literatos aprisionados em escolas" que já não respondiam mais aos paradigmas daquele "novo mundo" que estava se originando com o advento da modernização.

[...] Filhos do sol, mãe dos viventes. Encontrados e amados ferozmente, com toda a hipocrisia da saudade, pelos emigrados, pelos traficados e pelos touristes. No país da cobra grande. Foi porque nunca tivemos gramáticas, nem coleções de velhos vegetais. E nunca soubemos o que era urbano, suburbano, fronteiriço e continental. Preguiçosos no mapa-múndi do Brasil (ANDRADE, 1928).

Oswald de Andrade, um dos organizadores da Semana de 22, voltou da Europa para o Brasil em 1912, com o desejo de colocar em prática, seja na poesia ou nas artes em geral, tudo o quanto aprendeu. Oswald ficou impressionado com o Manifesto Futurista de Marinetti. Ele anunciou o compromisso da literatura com a nova civilização técnica, pregando o combate ao academicismo, guerreando contra quinquilharias e museus e exaltando o culto às "palavras em liberdade".

Oswald, influenciado pela atitude rebelde de Marinetti, compõe um poema de versos livres, cujo original provocou muitas arreliações. O poema se intitulava "Último passeio de um tuberculoso, pela cidade, de bonde" (1912):

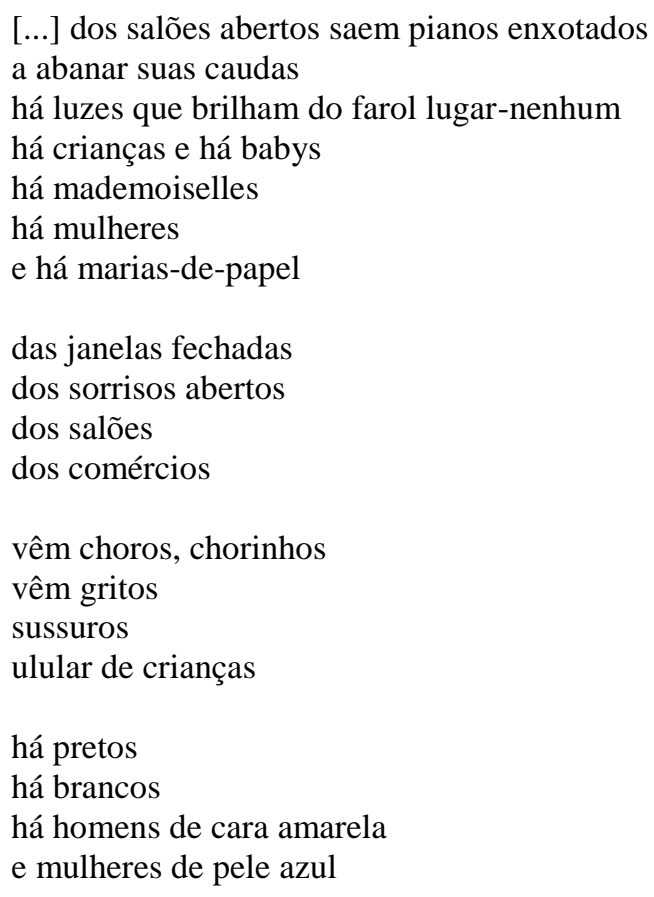




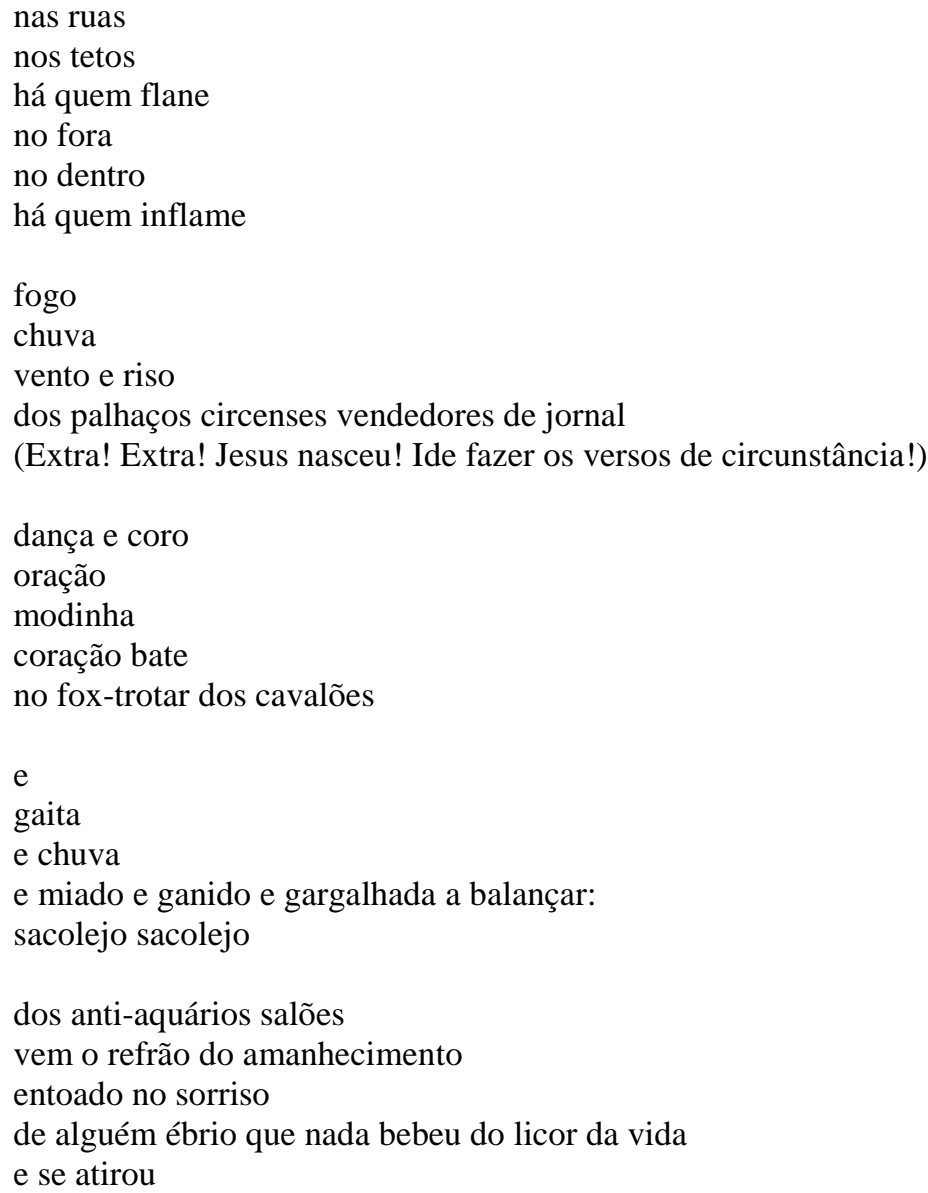

Este poema tinha uma inspiração urbana, era descritivo, mais lírico do que romântico, sem rima e sem métrica. Oswald desejava não só afrontar, mas também revolucionar as letras nacionais:

[...] O desejo de atualizar as letras nacionais - apesar de para tanto ser preciso importar ideias nascidas em centros culturais mais avançados - não implicava na renegação do sentimento brasileiro - aplicação de novos processos artísticos às aspirações autóctones, e, concomitantemente, a colocação do país, então sob notável influxo de progresso, nas coordenadas abertas pela nova era (COUTINHO, 1986, p. 5).

As palavras "futurismo" e "futurista", de grande circulação pelo mundo, já assinalavam sua presença no Brasil no jornal $O$ Estado de S. Paulo. O colaborador do jornal Ernesto Bertarelli, analisando as lições do futurismo, afirmava que se estava em face de um movimento lógico e benéfico (COUTINHO, 1986, p. 5).

O termo futurista começaria a ser vulgarizado e utilizado em vão, a exemplo de charges, frases e títulos de artigos: falava-se em economia futurista, um grupo de arruaceiros era também um grupo de futuristas. No editorial do jornal $A$ noite percebemos como a conceituação do termo transformara-se numa questão intrigante para a sociedade paulistana:

Futurismo!...futuristas! Que vem a ser isto, que vem a ser aquilo? 
Não sabemos e acreditamos que os leitores também não saibam. Para nós, os leigos, o futurismo é tudo quanto é extravagante e futurista todo indivíduo que, escrevendo, pintando, esculpindo e compondo pratica a extravagância. [...] A verdade é que o futurismo está agitando as cabeças. Na Europa, está ele a invadir tudo, os jornais, as revistas, as livrarias, os magazines de moda, os salões "chics". Dizem até que já empolgou a arquitetura e que está caminhando para invadir as cozinhas. Já há edifícios futuristas em Paris, já há molhos futuristas nos restaurantes parisienses (apud IEB, p. 232).

Muitos modernistas se irritavam em entrevistas com o estereótipo de "futurista", como Mário de Andrade assinalou em um depoimento para o jornal O Estado de S.Paulo (1922):

[...] Não sou futurista (de Marinetti). Disse e repito-o. Tenho pontos de contato com o futurismo. Oswald de Andrade, chamando-me de futurista errou. A culpa é minha. Sabia da existência do artigo e deixei que saísse. Tal foi o escândalo, que desejei a morte do mundo. Era vaidoso. Quis sair da obscuridade. Pensei que se discutiriam minhas ideias (que nem são minhas): discutiram minhas intenções. Já agora não me calo. Tanto ridicularizariam meu silêncio como esta grita (apud IEB, 1972, p.190).

Comentário feito a respeito do depoimento de Mário de Andrade para o suplemento $O$ mês modernista do jornal A noite, explica claramente sua reação em associá-lo ao futurismo:

[...] Não, não somos futuristas, afirmou o papa deles, o Sr. Mário de Andrade, em S. Paulo. O "futurismo", disse-nos o autor da Escrava que não é Isaura, é uma tola escola italiana que já desapareceu. O que há no Brasil, o que eles e os seus companheiros fazem é modernismo, isto é, guerra ao passadismo (apud IEB, 1972, p.232).

$\mathrm{Na}$ mesma época das discussões sobre o que seria moderno e sua relação com o futurismo, estavam ocorrendo em São Paulo outras manifestações artísticas do mesmo cunho inovador: Lasar Segall exibe em 1913 a primeira exposição de pintura não acadêmica; Anita Malfatti volta da Europa expondo seus trabalhos com influência da moderna Escola Alemã; os poetas Luís da Silva Ramos (de origem portuguesa) e Ronald de Carvalho produziam a revista Orfeu que, sob a tutela de Camilo Pessanha, Verlaine e Mallarmé, Walt Whitman, Marinetti e Picasso, comunicavam aos leitores uma nova mensagem brasileira.

Essas sementes inovadoras começaram a florescer com o evento da Semana de Arte Moderna realizada em 13 de fevereiro de 1922. Nessa ocasião, Graça Aranha abre o evento com uma palestra sobre a emoção estética na arte moderna e, no segundo dia, o palestrante Menotti del Picchia faria um discurso idealista, nativista, modernista e militante:

[...] Nada de postiço, meloso, artificial, arrevesado, precioso; queremos escrever com sangue - que é humanidade; com eletricidade - que é movimento, expressão dinâmica do século; violência - que é energia bandeirante. Assim nascerá uma arte genuinamente brasileira, filha do céu e da terra, do homem e do mistério. [...] Hoje que em Rio Preto o cowboy nacional reproduz, no seu cavalo chita, a epopeia equestre dos Rolandos furibundos; que o industrial de visão aquilina amontoa milhões mais vistosos do que os de Creso; que Edu Chaves reproduz com audácia paulista o sonho de Ícaro, por que não atualizarmos nossa arte, cantando essas Ilíadas Brasileiras? Por 
que preferirmos uma Atenas cujos destroços de Acrópole já estão pontilhados de balas de metralhadoras? Não! Paremos diante da tragédia hodierna, a cidade tentacular radica seus gânglios numa área territorial que abriga 600 mil almas. Há na angústia e na glória de sua luta odisseias mais formidáveis que as que cantou o aedo cego. [...] Tudo isto - e o automóvel, os fios elétricos, as usinas, os aeroplanos, a arte - tudo isso forma os nossos elementos da estética moderna, fragmentos de pedra em que construiremos dia-a-dia, a Babel do nosso Sonho, no nosso desespero de exilados de um céu que fulge lá em cima, para o qual galgamos na ânsia devoradora de tocar com as mãos as estrelas! (Apud SEVCENKO, 1992, p. 270).

Frente às manifestações negativas, advindas das alas conservadoras da sociedade paulistana, Ronald de Carvalho escreve sobre a vitória dos modernistas, não só com a Semana de Arte, mas também com o lançamento da Revista Klaxon:

[...] Após a famosa "Semana de Arte Moderna", organizada e dirigida por Graça Aranha, em que os filisteus colaboraram, na medida de suas forças, com balões de assobio, piadas medrosas de caixeiro endomingado, latidos, miados e cocoricós, capazes de justificarem as mais arrojadas teorias da metempsicose, os "independentes" de S. Paulo não cruzaram os braços. Levantaram os martelos e começaram a malhar. Os insultos acudiram com riso, um riso largo e generoso, de pena e ironia. Mario de Andrade, Menotti del Picchia, Oswald de Andrade, Guilherme de Almeida, Sergio Milliet, Rubens de Moraes, Couto de Barros, Buarque de Holanda, e poucos mais, foram os prógonos da batalha (apud IEB, 1972, p.198).

Apesar da repercussão negativa da Semana de Arte Moderna e de que muitas obras expostas não eram consideradas modernas, pôde-se considerar o evento como um movimento de vanguarda, na medida em que refletia uma nova situação não só na arte e na literatura, como também induzia a colocação de um país que pretendia ser autêntico, por isso antropofágico, assimilando influências externas e internas e confluindo, assim, num Matriarcado de Pindorama eclético que ainda se indagava: "tupi or not tupi that is the question?"

\section{Considerações finais}

[...] A Alegria é a prova dos nove. No Matriarcado de Pindorama. Contra a memória fonte de costume. A experiência pessoas renovada. Somos concretistas. As ideias tomam conta, reagem, queimam gente nas praças públicas. Suprimamos as ideias e as outras paralisias. Pelos roteiros. Acreditar nos sinais, acreditar nos instrumentos e nas estrelas. Contra Goethe, a mãe dos Gracos, e a Corte de D.João. A alegria é a prova dos nove. (...) Oswald de Andrade (trecho do Manifesto Antropofágico-1928).

"Dormir quando se tem sono, banhar-se quando estiver sujo, trabalhar quando for necessário, festejar-rir-brincar-dançar e se pintar a maior parte do tempo, beber quando se tem sede e devorar quando se tem fome..." (grifo nosso) principalmente se o inimigo for esteticamente e festivamente reaproveitado: Filiação. O contato com o Brasil Caraíba. Ori Villegaignon print terre. Montaigne. O homem natural. Rousseau. Da Revolução Francesa ao Romantismo, à Revolução Bolchevista à Revolução Surrealista e ao bárbaro tecnizado de Keyserling. Caminhamos... (ANDRADE, 1928) 
Tal como nossos ancestrais indígenas, Oswald de Andrade inaugura a "antropofagia cultural" que, ao invés de excluir "o outro", devora-o, sem culpa. Essa consciência lúdica e festiva seria um importante código identitário brasileiro, prescrito no Manifesto Antropofágico de Oswald, quando a carnavalização é assumida e radicalizada como postura consciente e norteadora de uma proposta estética.

A carnavalização presente na vida e no mundo é de grande pertinência para a formulação de uma identidade cultural brasileira, referindo-se ao mundo das transgressões e das intervenções onde se trocariam os papéis sociais e sexuais num verdadeiro "mundo às avessas".

Essa carnavalização ou o "mundo às avessas" é uma das temáticas principais da obra de Oswald de Andrade. Quando ele assina, localiza e data o manifesto antropofágico: Em Piratininga Ano 374 da Deglutição do Bispo Sardinha, refaz um mundo, onde o dominador é devorado pelo dominado e o "outro" passa a ser o europeu, o qual não é anulado da história brasileira, pois "revive" dentro do corpo indígena, que adquire toda a sua suposta virtude.

Há na poesia oswaldiana a voracidade da estética antropofágica que dialeticamente "constrói/reconstrói", como percebemos no prefácio que Paulo Prado escreveu para o Manifesto Pau-Brasil:

[...] A poesia 'pau-brasil' é, entre nós, o primeiro esforço organizado para a libertação do verso brasileiro [...] um período de construção criadora sucede agora as lutas da época de destruição revolucionária, das 'palavras em liberdade' [...] Sejamos agora de novo, no cumprimento de uma missão étnica e protetora jacobinamente brasileiros. Libertemo-nos das influências nefastas das velhas civilizações em decadência [...] Esperemos também que a poesia 'pau-brasil' extermine de vez um dos grandes males da raça - o mal da eloqüência balofa e roçagan-te [...] (PRADO apud MIRANDA, 1997, p.137).

A nova linguagem poética que aflorava estaria intimamente relacionada àquela da sociedade industrial e à tecnologia que podia ser visualizada nas artes, como no cinema, por exemplo, com sua linguagem fragmentada, com a montagem de imagens múltiplas. Oswald argumenta sobre o surgimento de "um novo mundo" resultante da modernização:

\footnotetext{
Houve um fenômeno de democratização estética nas cinco partes sábias do mundo (...) veio a pirogravura. As meninas de todos os lares ficaram artistas (...). Apareceu a máquina fotográfica. E com todas as prerrogativas do cabelo grande, da caspa e da misteriosa genialidade de olho virado - o artista fotógrafo. Na música, o piano invadiu as saletas nuas, de folhinha na parede. Todas as meninas ficaram pianistas. Surgiu o piano de manivela, o piano de patas. A pleyelá. E a ironia eslava compôs para a pleyela. Stravinski. A estatuária andou atrás. As procissões saíram novinhas das fábricas (Apud MIRANDA, 1997, p.138).
}

"Ser regional e puro em sua época". Com esta máxima colocava-se a questão da concepção oswaldiana acerca do regionalismo e do nativismo indígena. Para Oswald, ser 
regional não significaria ser restrito e limitado, pois havia uma relação dialética entre o regional e o universal. Assim sendo, ser regional era também ser universal e vice-versa.

A democratização de bens culturais advindos da tecnologia, o caráter conservador das letras brasileiras, os parnasianos, os românticos, Olavo Bilac e o bispo Sardinha, todos eles deveriam ser deglutidos e, a partir de então, haveria uma nova perspectiva para se entender e pensar o Brasil. Oswald esclareceria através de sua visão carnavalizada que: Nunca fomos catequizados. Fizemos foi carnaval. O índio vestido de senador do Império. Fingindo de Pitt. Ou figurando nas óperas de Alencar cheio de bons sentimentos portugueses. Este é o Brasil que Oswald escrevera em seu Manifesto antropofágico (1928) e que posteriormente seria "deglutido" pelo Movimento Tropicalista.

(Artigo enviado em 14/07/2014, aprovado em 29/07/2014)

\section{Referências}

ANDRADE, Oswald de. Seleção de textos, notas, estudo biográfico, histórico e crítico de exercícios por Jorge Schwartz. São Paulo: Abril Educação, 1980.

BRITO, Mário da Silva. História do Modernismo Brasileiro: Antecedentes da Semana de Arte Moderna. 3a. edição. Rio de Janeiro. Civilização Brasileira, 1971.

COUTINHO, Afrânio. A Literatura no Brasil. Volume V, parte II/estilos de época. A Era Modernista. José Olympio Editora. Rio de Janeiro/Niterói - 1986. 3a. edição. UFF Universidade Federal Fluminense.

INSTITUTO DE ESTUDOS BRASILEIROS - USP. Pesquisa, seleção e planejamento: Marta Rosset Batista, Telê Porto Ancona Lopes, Yone Soares de Lima. Brasil: 1o.tempo modernista. 1917/29. São Paulo, 1972, v. 26.

MIRANDA, Dilmar. Carnavalização e Multidentidade Cultural - Antropofagia e Tropicalismo. Tempo Social (Revista de Sociologia da USP), vol.9, no. 2. Outubro/1997.

PELEGRINI, Sandra de Cássia Araújo. Os anos 60: Um projeto político-cultural em debate. IN História, v.10. UNESP, 1991.

SCHWARCZ, Lilia Moritz. O espetáculo das raças: Cientistas, Instituições e questão racial no Brasil 1870-1930. São Paulo: Companhia das Letras, 1993.

SEVCENKO, Nicolau. Orfeu Extático na Metrópole: São Paulo, sociedade e cultura nos frementes anos 20. São Paulo: Cia das Letras, 1992. 